\title{
Errata: Optical fiber probe spectroscopy for laparoscopic monitoring of tissue oxygenation during esophagectomies
}

Daniel S. Gareau, ${ }^{\text {a }}$ Frederic Truffer, ${ }^{\text {a Kyle A. Perry, }},{ }^{b}$ Thai H. Pham, ${ }^{\text {b }}$ C. Kristian Enestvedt, ${ }^{b}$ James P. Dolan, ${ }^{b}$ John G. Hunter, ${ }^{b}$ and Steven L. Jacques ${ }^{c}$

${ }^{a}$ Oregon Health and Science University, Department of Biomedical Engineering, 3303 SW Bond Avenue, Portland, Oregon 97239

b'Oregon Health and Science University, Department of Surgery, 3181 SW Sam Jackson Park Road, Portland, Oregon 97239

'Oregon Health and Science University, Department of Biomedical Engineering, 3303 SW Bond Avenue, Portland, Oregon 97239

[DOI: $10.1117 / 1.3569120]$

This article [J. Biomed. Opt. 15, 061712 (2010)] was originally published online on 19 November 2010 with errors in the author list. Middle initials have been added to authors Perry, Pham, and Dolan.

All versions of the article were corrected on 1 Mar 2011. 